Elke Janssens · Peter Aerssens · Phillipe Alliët

Phillipe Gillis · Marc Raes

\title{
Post-dural puncture headaches in children. A literature review
}

Published online: 28 May 2003

(C) Springer-Verlag 2003

\section{Eur J Pediatr (2003) 162:117-121}

There was an error in the last but one paragraph of the conclusion. In the first sentence of this paragraph the word "perpendicularly" has to be replaced by "parallel".

The authors would like to apologise for this mistake. The correct sentence appears here:
Concerning technique, the bevel of the needle should be inserted parallel to the longitudinal dural fibres; the stylet replaced before withdrawing the needle; the number of attempted punctures kept as low as possible and the smallest amount of CSF as possible removed, definitely not more than $15 \mathrm{ml}$.

The online version of the original article can be found at http:// dx.doi.org/10.1007/s00431-002-1122-6

E. Janssens

Department of Paediatrics, Catholic University of Leuven, Leuven, Belgium

P. Aerssens · P. Alliët · P. Gillis · M. Raes $(\bowtie)$

Paediatric Department, Virga Jesseziekenhuis, Stadsomvaart 11, 3500 Hasselt, Belgium

E-mail: dr.raes.marc@wanadoo.be

Tel.: +32-11-308111 